OPEN ACCESS

Edited by:

Ajar Nath Yadav,

Eternal University, India

Reviewed by:

Divjot Kour

Southern Federal University, Russia

Deep Chandra Suyal,

Eternal University, India

*Correspondence:

Yu-Lan Jiang

yljchsd@163.com

Guang-Can Tao

tgcan@gzata.cn

${ }^{\dagger}$ These authors share first authorship

Specialty section:

This article was submitted to Microbe and Virus Interactions with

Plants,

a section of the journal

Frontiers in Microbiology

Received: 09 August 2021 Accepted: 08 November 2021 Published: 29 November 2021

Citation:

Zhang H, Wei T-P, Li L-Z, LuO M-Y,

Jia $W-Y$, Zeng $Y$, Jiang $Y-L$ and Tao G-C (2021) Multigene Phylogeny, Diversity and Antimicrobial Potential of Endophytic Sordariomycetes From

Rosa roxburghii.

Front. Microbiol. 12:755919. doi: 10.3389/fmicb.2021.755919

\section{Multigene Phylogeny, Diversity and Antimicrobial Potential of Endophytic Sordariomycetes From Rosa roxburghii}

\author{
Hong Zhang ${ }^{1,2 t}$, Tian-Peng Wei't, Lin-Zhu Li' ${ }^{2}$, Ming-Yan Luo ${ }^{1}$, Wei-Yu Jia', Yan Zeng ${ }^{1}$, \\ Yu-Lan Jiang ${ }^{1 *}$ and Guang-Can Tao ${ }^{2,3 *}$ \\ 'Department of Plant Pathology, College of Agriculture, Guizhou University, Guiyang, China, ${ }^{2}$ Guizhou Academy of Testing \\ and Analysis, Guiyang, China, ${ }^{3}$ Food Safety and Nutrition (Guizhou) Information Technology Co., Ltd., Guiyang National \\ High-Tech Industrial Development Zone, Guiyang, China
}

Rosa roxburghii Tratt. is widely applied in food, cosmetics, and traditional medicine, and has been demonstrated to possess diverse bioactivities. Plant endophytic fungi are important microbial resources with great potential for application in many fields. They not only establish mutualistic symbiosis with host plants but also produce a variety of bioactive compounds. Therefore, in the present study, endophytic fungi were isolated from $R$. roxburghii, the diversity and antimicrobial activities were evaluated. As a result, 242 strains of endophytic Sordariomycetes were successfully isolated. Multigene phylogenetic analyses showed that these isolates included eight orders, 19 families, 33 genera. The dominant genera were Diaporthe (31.4\%), Fusarium (14.4\%), Chaetomium (7.9\%), Dactylonectria (7.0\%), Graphium (4.5\%), Colletotrichum (4.1\%), and Clonostachys (4.1\%). For different tissues of $R$. roxburghii, alpha diversity analysis revealed that the diversity of fungal communities decreased in the order of root, fruit, stem, flower, leaf, and seed, and Clonostachys and Dactylonectria exhibited obvious tissue specificity. Meanwhile, functional annotation of 33 genera indicated that some fungi have multitrophic lifestyles combining endophytic, pathogenic, and saprophytic behavior. Additionally, antimicrobial activities of endophytic Sordariomycetes against Lasiodiplodia theobromae, Botryosphaeria dothidea, Colletotrichum capsici, Pyricularia oryzae, Rhizoctonia solani, Fusarium oxysporum, Pseudomonas syringae, Pantoea agglomerans, Staphylococcus aureus, Bacillus subtilis, Escherichia coli, and Pseudomonas aeruginosa were screened. Dual culture test assays showed that there were 40 different endophytic species with strong inhibition of at least one or moderate inhibition of two or more against the 12 tested strains. The results from the filter paper diffusion method suggested that extracellular metabolites may be more advantageous than intracellular metabolites in the development of antimicrobial agents. Eleven isolates with good activities were screened. In particular, Hypomontagnella monticulosa HGUP194009 and Nigrospora sphaerica HGUP191020 have shown promise in both broad-spectrum and intensity. Finally, some fungi that commonly cause disease have 
been observed to have beneficial biological activities as endophytic fungi. In conclusion, this study showed the species composition, alpha diversity, and lifestyle diversity of endophytic Sordariomycetes from $R$. roxburghii and demonstrated these isolates are potential sources for exploring antimicrobial agents.

Keywords: molecular phylogeny, alpha diversity, lifestyle diversity, intracellular metabolites, extracellular metabolites, Hypomontagnella monticulosa, Nigrospora sphaerica

\section{INTRODUCTION}

Endophytic fungi are highly diverse taxa of microorganisms that inhabit asymptomatically in healthy tissues of living plants (Jia et al., 2016), and are currently not completely explored. They have increasingly received much attention due to their biological activities, such as antifungal, antibacterial, antivirus, insecticides, antioxidant, cytotoxic, alpha-glucosidase inhibitory, anti-inflammation, antidiabetic, and anticancer properties (Deshmukh et al., 2015; Zhang et al., 2019; Fernando et al., 2020; Manganyi and Ateba, 2020; Pal et al., 2020; Peng et al., 2020; Rahaman et al., 2020; Agrawal et al., 2021). In the field of plant protection, fungal endophytes are considered as one of the most important sources of potential biocontrol agents because of antimicrobial, antivirus, insecticides, and the alleviation of abiotic stresses (Park et al., 2017; Wen et al., 2019). They can reduce disease severity and pathogen biomass in the host plant via nutrient and space competition and producing various antagonistic secondary metabolites (Rojas et al., 2020; Xie et al., 2020). These metabolites showed inhibitory activity against the spore germination of the pathogens and were also able to cause morphological changes, reduced the expression of the genes involved in mycelial growth and virulence, and induced defense-related genes (Park et al., 2015; Sánchez-Fernández et al., 2020). So, biological control based on fungal endophytes and their functional secondary metabolites has broad application prospects. Meanwhile, endophytic fungi are also well known as a source of antimicrobial agents for pharmaceutical development.

Sordariomycetes, the second-largest class of the phylum Ascomycota, including 28 orders, 90 families and 1,344 genera, 829 uncertain genera, and over 10,000 species, is also the dominant community member of endophytic fungi from various plants (Fonseca-García et al., 2016; Maharachchikumbura et al., 2016). Some species of Sordariomycetes have also been considered important biocontrol agents, e.g., Trichoderma spp., Hypoxylon anthochroum and Induratia alba (syn. Muscodor albus), and others produce a variety of bioactive compounds that are important to the biotechnology industries (Leylaie and Zafari, 2018; Macías-Rubalcava et al., 2018; Tilocca et al., 2020).

Rosa roxburghii Tratt., an economically important crop of homologous medicine and food, is characterized by a notably high content of vitamin C, up to $1,000 \mathrm{mg} / 100 \mathrm{~g}$ (Xu et al., 2019). The wild $R$. roxburghii is mainly distributed in Southwest China, while it is only domesticated and cultivated on a large scale in Guizhou Province, China. In recent years, it was widely applied in food and cosmetics for its nutritional and health benefits (Yang et al., 2020). Its root, leaf, and fruit have been used as traditional medicinal materials in the treatment of several diseases, including strengthening the spleen, dyspepsia, enteritis, and scurvy (Wang et al., 2018). Modern pharmacological studies have demonstrated that some components of $R$. roxburghii exhibited several biological activities, such as excellent hypoglycemic and hypolipidemic effects, enhancing immunity, antioxidation, and anti-tumor activities (Wang et al., 2018).

Given the high dietary and medicinal value of $R$. roxburghii and there have been few investigations of endophytes isolated from this plant, in this study, we selected it as a source plant to isolate culturable endophytes through different media. We further assessed the diversity and antimicrobial potential of endophytic Sordariomycetes. This work will aid in the search for novel endophytic species or strains that possess valuable bioactive compounds and also set the basis for the foundation of promoting growth and improving immunity and stress resistance of $R$. roxburghii.

\section{MATERIALS AND METHODS}

\section{Isolation and Identification}

\section{Sample Collection and Endophyte Isolation}

From April to August 2020, Healthy R. roxburghii tissues were collected from Guiyang City $\left(27^{\circ} 4^{\prime} 50^{\prime \prime} \mathrm{N}, 106^{\circ} 29^{\prime} 50^{\prime \prime} \mathrm{E}\right)$ and Liupanshui City $\left(25^{\circ} 52^{\prime} 52^{\prime \prime} \mathrm{N}, 104^{\circ} 33^{\prime} 59^{\prime \prime} \mathrm{E}\right)$, Guizhou Province, China. Endophytic fungi were isolated from the sample blocks according to the method described by Liu et al. (2015). To isolate as many endophytes as possible, six different media, including potato dextrose agar (PDA), oatmeal agar (OA), malt extract agar (MEA), Czapek Dox Agar (CDA), water agar (WA), and synthetic low nutrient agar (SNA) medium, were used for isolation.

\section{DNA Extraction, Polymerase Chain Reaction Amplification, and Sequencing}

DNA was extracted from fresh mycelia grown on PDA using the Fungal gDNA Isolation Kit (BW-GD2416, Biomiga, China), following the manufacturer's instructions. The extracted DNA was used as the template for the polymerase chain reaction (PCR). The primers and PCR reaction conditions were given in Table 1. The amplified PCR products were directed to Sangon Biotech (Shanghai) Co., Ltd. (Shanghai, China) for sequencing.

\section{Multigene Phylogenetic Analyses}

Endophytic fungi were identified by protein-coding and ribosomal gene sequences. All forward and reverse sequences were used to create consensus sequences by BioEdit v. 7.0.9.0 (Hall, 1999), and BLASTn searched in NCBI to identify genuslevel taxonomic status. Multigene phylogenetic analyses were 
TABLE 1 | Details of genes/loci with PCR primers and PCR profiles.

\begin{tabular}{|c|c|c|}
\hline Gene/Loci & PCR primers (forward/reverse) & PCR condition \\
\hline ITS & ITS5/ITS4 & $94^{\circ} \mathrm{C}: 3 \mathrm{~min}, 35$ cycles $\left(94^{\circ} \mathrm{C}: 30 \mathrm{~s}, 55^{\circ} \mathrm{C}: 30 \mathrm{~s}, 72^{\circ} \mathrm{C}: 45 \mathrm{~s}\right), 72^{\circ} \mathrm{C}: 10 \mathrm{~min}$, final hold at $4^{\circ} \mathrm{C}$ \\
\hline LSU & LROR/LR5 & $94^{\circ} \mathrm{C}: 3 \mathrm{~min}, 35$ cycles $\left(94^{\circ} \mathrm{C}: 30 \mathrm{~s}, 55^{\circ} \mathrm{C}: 30 \mathrm{~s}, 72^{\circ} \mathrm{C}: 45 \mathrm{~s}\right), 72^{\circ} \mathrm{C}: 10 \mathrm{~min}$, final hold at $4^{\circ} \mathrm{C}$ \\
\hline TUB & $\mathrm{Bt} 2 \mathrm{a} / \mathrm{Bt} 2 \mathrm{~b}$ & $95^{\circ} \mathrm{C}: 5 \mathrm{~min}, 35$ cycles $\left(94^{\circ} \mathrm{C}: 1 \mathrm{~min}, 55^{\circ} \mathrm{C}: 1 \mathrm{~min}, 72^{\circ} \mathrm{C}: 2 \mathrm{~min}\right), 72^{\circ} \mathrm{C}: 10 \mathrm{~min}$, final hold at $4^{\circ} \mathrm{C}$ \\
\hline
\end{tabular}

performed by Maximum Likelihood (ML) and Bayesian inference (BI) methods. The sequences were aligned with MAFFT v. 7 (Katoh et al., 2019). Alignments were adjusted manually in BioEdit v. 7.0.9.0 (Hall, 1999) and concatenated in PhyloSuite v. 1.2.2 (Zhang D. et al., 2020). The best-fit partition models were inferred using ModelFinder (Kalyaanamoorthy et al., 2017), ML was conducted using IQ-TREE (Nguyen et al., 2014), BI was carried out using MrBayes 3.2.6 (Ronquist et al., 2012), and they have been integrated into PhyloSuite (Zhang D. et al., 2020).

\section{Diversity Indices and Functional Annotations Analysis}

\section{Dominant Taxa}

A taxon is defined as dominant if $P_{i}>$ Camargo's index $(1 / S)$, where $S$ represents species richness, which is the number of fungal taxa, $P_{i}$ is calculated as the number of isolates $\left(N_{i}\right)$ that belong to a certain taxon $(i)$ divided by the total number of isolates $(N)$ (Camargo, 1992; Kusari et al., 2013).

\section{Alpha Diversity}

To quantify the alpha diversity of endophytic Sordariomycetes from $R$. roxburghii in different tissues, the Shannon-Wiener index $\left(H^{\prime}\right)$, Simpson index $(D)$, Margalef index $(d M)$, and Pielou evenness index $(J)$ were calculated using the following equations, respectively (Kusari et al., 2013; Li et al., 2016):

$$
\begin{aligned}
& H^{\prime}=-\sum_{i=1}^{S}\left(P_{i}\right)\left(\ln P_{i}\right) \\
& D=1-\sum_{i=1}^{S}\left(P_{i}\right)^{2} \\
& d M=(S-1) / \ln N \\
& J=H^{\prime} / H_{\text {max }}^{\prime}, H_{\text {max }}^{\prime}=\ln S
\end{aligned}
$$

Where, $P_{i}, S$, and $N$ as described above.

\section{Lifestyle Diversity}

Lifestyle status for culturable fungi was predicated using the FUNGuild database ${ }^{1}$. Functional annotation of fungi at the genus level was considered reasonable (Nguyen et al., 2016).

\section{Antimicrobial Activity Tested Strains}

Twelve tested strains were used to evaluate antimicrobial potential of endophytic Sordariomycetes. Six phytopathogenic fungi (Lasiodiplodia theobromae, Botryosphaeria dothidea,

\footnotetext{
${ }^{1}$ http://funguild.org
}

Colletotrichum capsici, Pyricularia oryzae, Rhizoctonia solani, and Fusarium oxysporum), two phytopathogenic bacteria (Pseudomonas syringae pv. actinidiae, and Pantoea agglomerans), two Gram-positive bacteria [Staphylococcus aureus, ATCC 6538; and Bacillus subtilis, CMCC (B) 63501], and two Gramnegative [Escherichia coli, CMCC (B) 44102; and Pseudomonas aeruginosa, ATCC 27853].

\section{Preliminary Antimicrobial Screening}

Preliminary screening assays for antifungal activity were performed following the method of Singh et al. (2020). Briefly, mycelial plugs $(6 \mathrm{~mm})$ of tested fungi were inoculated at the center of PDA plates, the plugs $(6 \mathrm{~mm})$ of endophyte strains were placed at the edge of PDA plates. All plates were incubated for 2-7 days at $28 \pm 1^{\circ} \mathrm{C}$. Thereafter, the width of inhibitory bands $(I)$ between tested fungi and endophytes was measured, with three replicates. $0(I=0)$, no inhibition; $1(0<I \leq 1 \mathrm{~mm})$, weak inhibition; 2 ( $1 \mathrm{~mm}<I \leq 3 \mathrm{~mm})$, moderate inhibition; 3 ( $I>3 \mathrm{~mm}$ ), strong inhibition (Zhao et al., 2019).

Preliminary antibacterial screening assays were carried out by inoculation of endophytic fungi with mycelial plugs. Mycelial plugs $(6 \mathrm{~mm})$ were placed symmetrically on nutrient agar (NA) plates, which were already coated with tested bacteria. The width of inhibitory bands $(I)$ between tested bacteria and endophytes was measured after culturing for $48 \mathrm{~h}$ at $25 \pm 1^{\circ} \mathrm{C}$ for phytopathogenic bacteria, $35 \pm 1^{\circ} \mathrm{C}$ for other bacteria, with three replicates. 0 ( $I \leq 1 \mathrm{~mm})$, no inhibition; $1(1 \mathrm{~mm}<I \leq 2 \mathrm{~mm})$, weak inhibition; 2 ( $2 \mathrm{~mm}<I \leq 10 \mathrm{~mm})$, moderate inhibition; 3 ( $I>10 \mathrm{~mm}$ ), strong inhibition (Gashgari et al., 2016).

\section{Extracellular and Intracellular Metabolite Extraction}

Following molecular identification and preliminary screening, strains would be selected for further study by the following principles: (1) with the best inhibition effect in the same species; (2) strong inhibition of at least one or moderate inhibition of two or more against the 12 tested strains.

Strains that screened according to the above principles were inoculated separately into $250 \mathrm{~mL}$ Erlenmeyer flasks with $100 \mathrm{~mL}$ of potato dextrose broth (potato: $200 \mathrm{~g} / \mathrm{L}$; dextrose: $20 \mathrm{~g} / \mathrm{L}$; natural $\mathrm{pH})$. These flasks were cultured in a rotating incubator $\left(28 \pm 1^{\circ} \mathrm{C}, 220 \mathrm{rpm}\right)$ for $7-10$ days. The fermentation broth was then separated from the mycelium by vacuum filtration or high-speed centrifugation $(12,000 \mathrm{rpm})$. The culture broth was extracted three times with the same volume of ethyl acetate (EtOAc). The mycelium was extracted with $150 \mathrm{~mL}$ of methanol $(\mathrm{MeOH})$ under ultrasonication for $1 \mathrm{~h}$. The suspension was filtered and the mycelium was discarded. Extracts were concentrated under reduced pressure using a rotary vacuum evaporator at $50^{\circ} \mathrm{C}$ until constant weight and dissolved in 
dimethyl sulfoxide (DMSO) to prepare $20 \mathrm{mg} / \mathrm{mL}$ of extracellular and intracellular metabolites. All crude extracts were stored at $-20^{\circ} \mathrm{C}$

\section{Re-screening of Antifungal Activity Assay}

Antifungal activity of extracellular and intracellular metabolites was re-screened according to $\mathrm{Hu}$ et al. (2017). Mycelial plugs $(6 \mathrm{~mm})$ of the tested fungi were inoculated on PDA plates,
$2 \mathrm{~cm}$ from the edge of the plates. Immediately afterward, sterile filter paper disks $(6 \mathrm{~mm})$ were placed at equal distances from the opposite edge, impregnated with $10 \mu \mathrm{L}$ of crude extract $(20 \mathrm{mg} / \mathrm{mL})$. DMSO was used as the negative control. All plates were incubated at $28 \pm 1^{\circ} \mathrm{C}$ for $2-7$ days. Radial growth of tested strains was measured. The percentage inhibition $(\%)=\left(R_{1}-R_{2}\right) / R_{1} \times 100 \%$ (Hajieghrari et al., 2008), where $R_{1}$ is radial growth measurement of the tested strains in control,

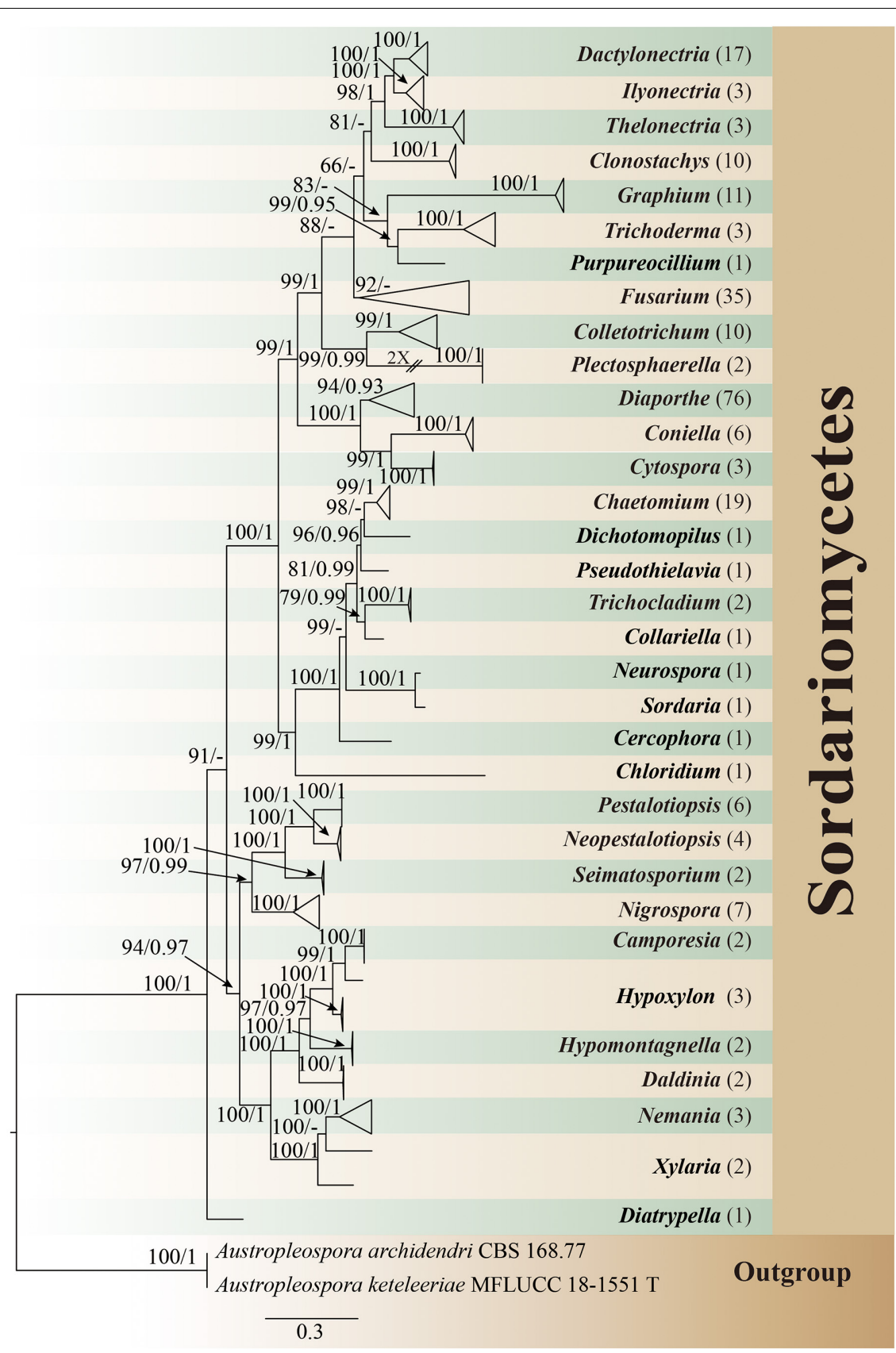

FIGURE 1 | Phylogram generated from maximum likelihood analysis based on combined ITS, LSU, and TUB sequence data of endophytic Sordariomycetes in this study. Austropleospora archidendri (CBS 168.77) and A. keteleeriae (MFLUCC 18-1551) are used as the outgroup taxa. Bootstrap support values for ML greater than $50 \%$, and Bayesian posterior probabilities greater than 0.90 are given near nodes (BS/PP), respectively. The number in brackets represents the number of endophytic isolates. T, type. 


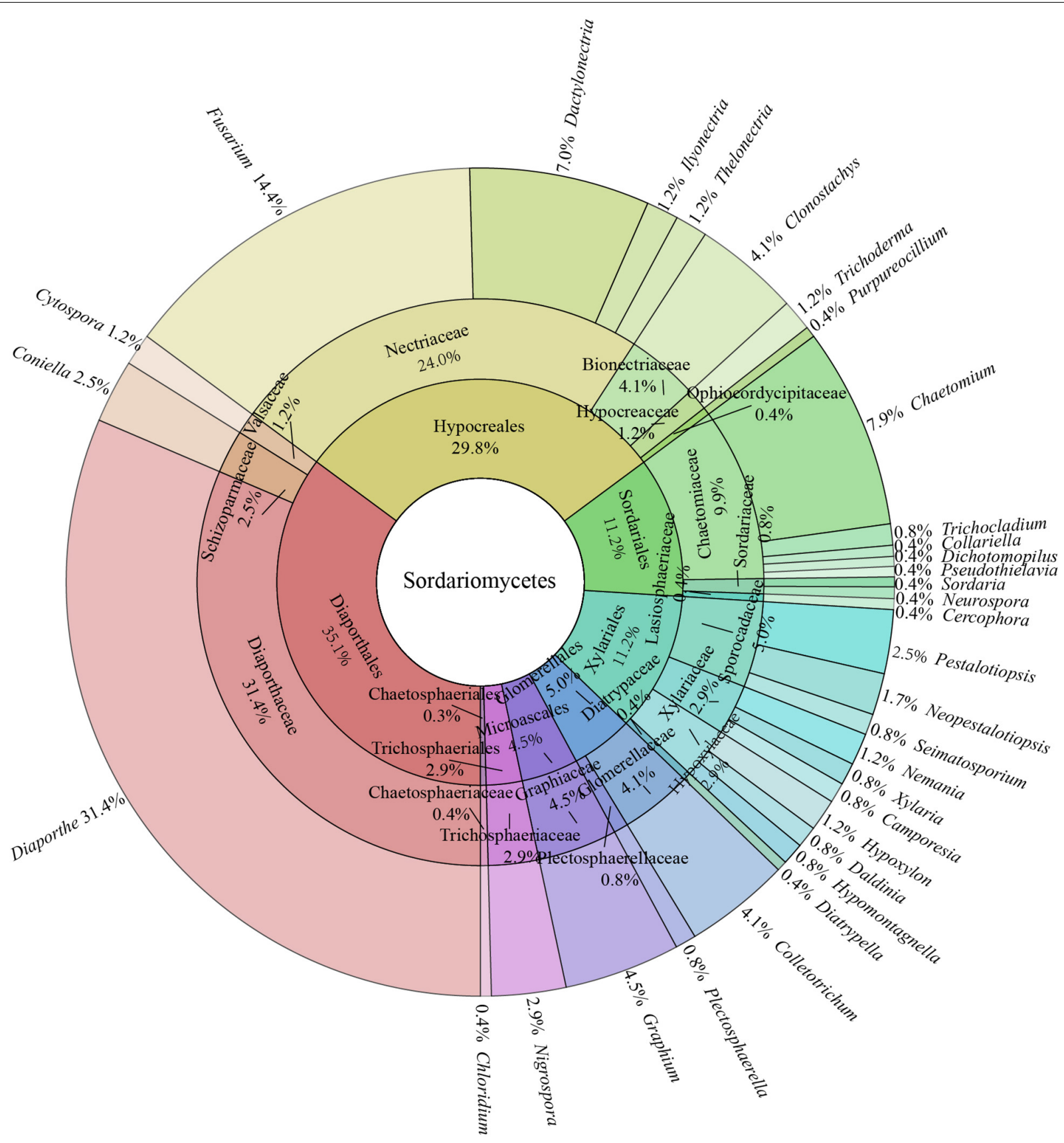

FIGURE 2 | Species composition of endophytic Sordariomycetes from Rosa roxburghii.

$\mathrm{R}_{2}$ is radial growth of the tested strains in the presence of metabolites. Similarly, the minimum inhibitory concentration (MIC) tests were performed.

\section{Re-screening of Antibacterial Activity Assay}

The filter paper disk diffusion method was used to rescreen the antibacterial activity of secondary metabolites (Rjeibi et al., 2020). Sterile filter paper disks $(6 \mathrm{~mm})$ were placed on the center of NA plates that had been coated with the tested bacteria. Then the disks were impregnated with
$10 \mu \mathrm{L}$ of metabolites $(20 \mathrm{mg} / \mathrm{mL})$. DMSO was applied as the negative control. Incubation conditions were the same as the preliminary screening, and the diameter of the inhibition zone was measured, with three replicates. Similarly, the MICs were determined.

\section{Data Analysis}

Statistical analyses were conducted using Data Processing System (DPS v9.50). Data were analyzed by ANOVA, followed by comparisons of means using the LSD test $(P<0.05)$. 


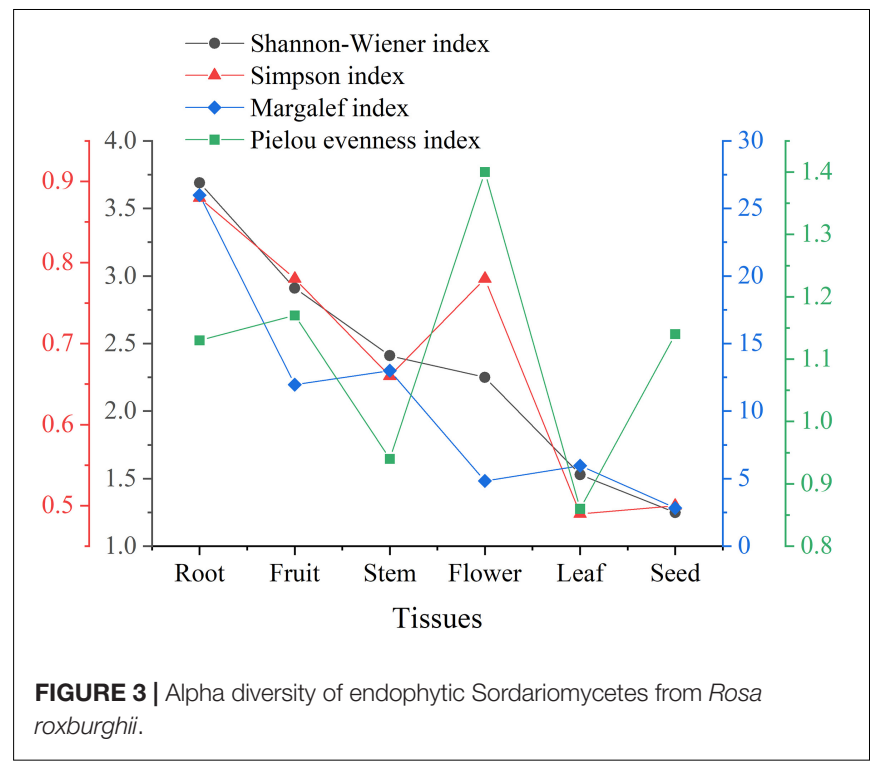

\section{RESULTS}

\section{Endophytic Sordariomycetes Identification}

All isolates were identified through multigene phylogenetic analysis of the combined internal transcribed spacer (ITS), $28 \mathrm{~S}$ large subunit rDNA (LSU), and beta-tubulin (TUB). A total of 242 isolates of endophytic Sordariomycetes were obtained and identified from the root, stem, leaf, flower, fruit, and seed segments of $R$. roxburghii. The phylogenetic relationship of these isolates was shown in Figure 1, containing eight orders, 19 families, 33 genera. One hundred and ninety of these (78.5\%) were identified at the species level, covering 69 confirmed species. The rest (21.5\%) were characterized at the genus level, including 30 unconfirmed species, possibly belonging to new taxa.

\section{Diversity of Endophytic Sordariomycetes Dominant Taxa}

In all isolates of endophytic Sordariomycetes, the Camargo's index $(1 / S)$ at the order, family, and genus level were $0.125,0.053$, and 0.030 , respectively. Therefore, the dominant orders were Diaporthales (35.1\%) and Hypocreales (29.8\%); the dominant families were Diaporthaceae (31.4\%), Nectriaceae (29.8\%), and Chaetomiaceae (9.9\%); and the dominant genera were Diaporthe (31.4\%), Fusarium (14.4\%), Chaetomium (7.9\%), Dactylonectria (7.0\%), Graphium (4.5\%), Colletotrichum (4.1\%), and Clonostachys (4.1\%) details as in Figure 2.

\section{Alpha Diversity}

The species diversity can be assessed by the Shannon-Wiener index $\left(H^{\prime}\right)$ and Simpson index $(D)$. In general, the higher the $H^{\prime}$ (usually ranging from 1.5 to 4.5 ) and the closer the $D$ to 1 , the more intensified heritable variation and the better the ability to adapt to micro-environmental changes. Margalef index $(d M)$ can reflect the richness of endophytic fungi species. The larger the $d M$, the more abundant the endophytic fungal species. Additionally, the Pielou evenness index $(J)$ can reflect the evenness of species (Li et al., 2016). Typically, the trends of $H^{\prime}$ and $d M$ remained consistent. However, as illustrated in Figure 3, the value of $D$ was higher in floral tissues than in stem tissues, which might be attributed to the higher values of $J$. The endophytic fungi in floral tissues (five species, six isolates) were much lower than in stem tissues (13 species, 72 isolates) in both species and number. In cases of poor diversity, as in seed tissue, the Pielou evenness index had little effect on the other indices.

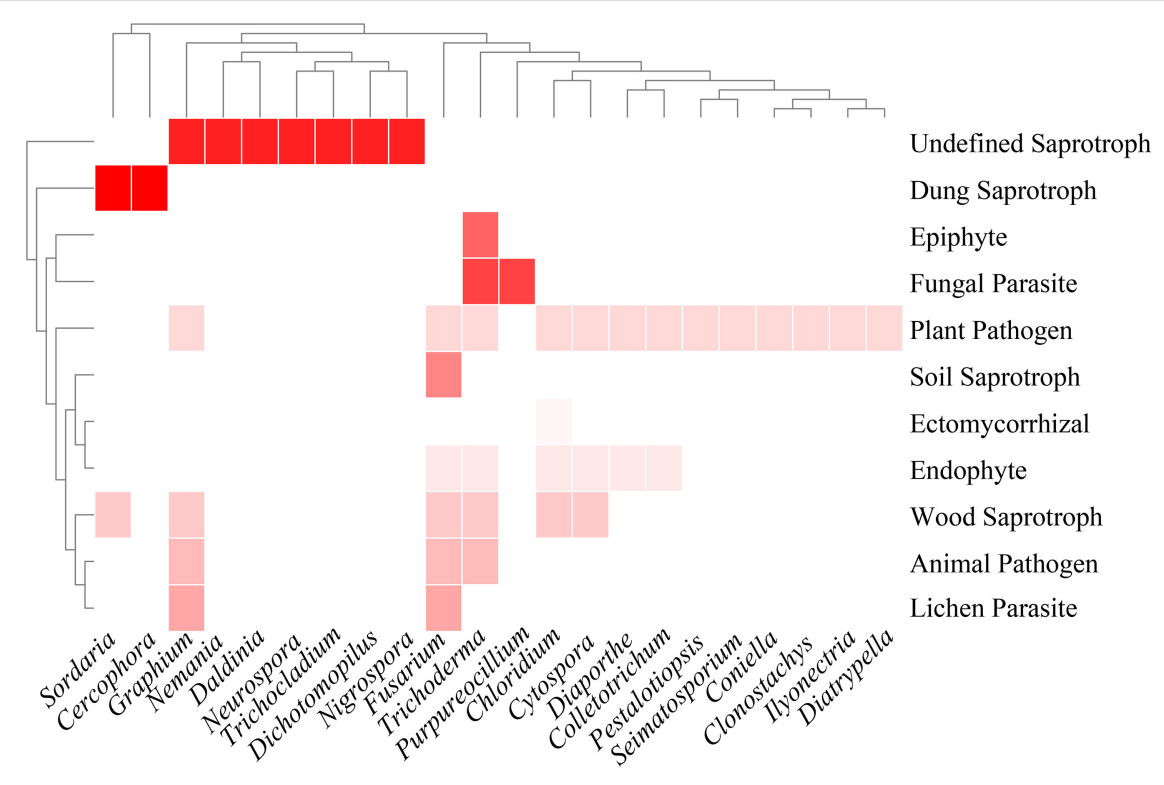

FIGURE 4 | Heatmap of functional annotations of culturable fungi. Different shades of red indicate different fungal lifestyles. 
Taken together, the diversity of endophytic Sordariomycetes from different tissues decreased in the order of root, fruit, stem, flower, leaf, and seed. Notably, both 10 isolates of Clonostachys and 17 isolates of Dactylonectria were present only in root tissues.

\section{Lifestyle Diversity}

Thirty-three genera of Sordariomycetes were analyzed for functional annotation in the FUNGuild database. Of these, no information was obtained in 11 genera, including Plectosphaerella, Dactylonectria, Thelonectria, Chaetomium, Collariella, Pseudothielavia, Xylaria, Hypomontagnella, Camporesia, Hypoxylon, and Neopestalotiopsis. Functional annotations of other genera were as described in Figure 4. Plant pathogen and saprotroph (wood saprotroph, soil saprotroph, dung saprotroph, and undefined saprotroph) dominated the fungal communities, followed by endophytic fungi (6/22). Five genera, namely Chloridium, Cytospora, Fusarium, Trichoderma, and Graphium, were found to have three or more lifestyles.

\section{Antimicrobial Activity}

\section{Preliminary Antimicrobial Screening}

In this study, 242 strains of endophytic Sordariomycetes were first screened for antimicrobial activity. There were 40 strains from different species that exhibited at least one strong inhibition or two or more moderate inhibition against the 12 tested strains, as presented in Figure 5. Almost all screened isolates (39/40) showed moderate and above inhibition against Bacillus subtilis. The same effect was observed for $70 \%$ (28/40) of these against Pseudomonas syringae pv. actinidiae. In addition, Pantoea agglomerans, Staphylococcus aureus, and

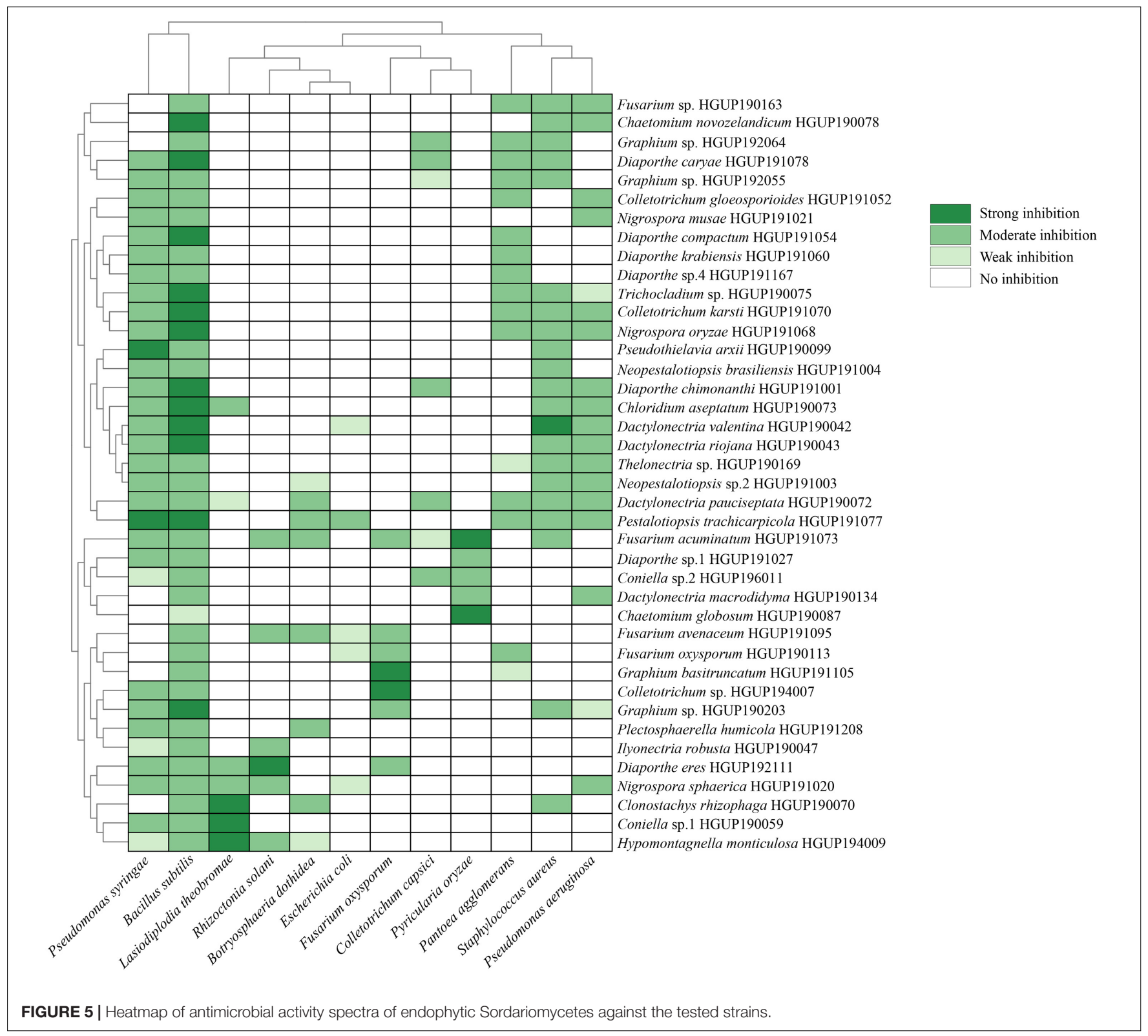




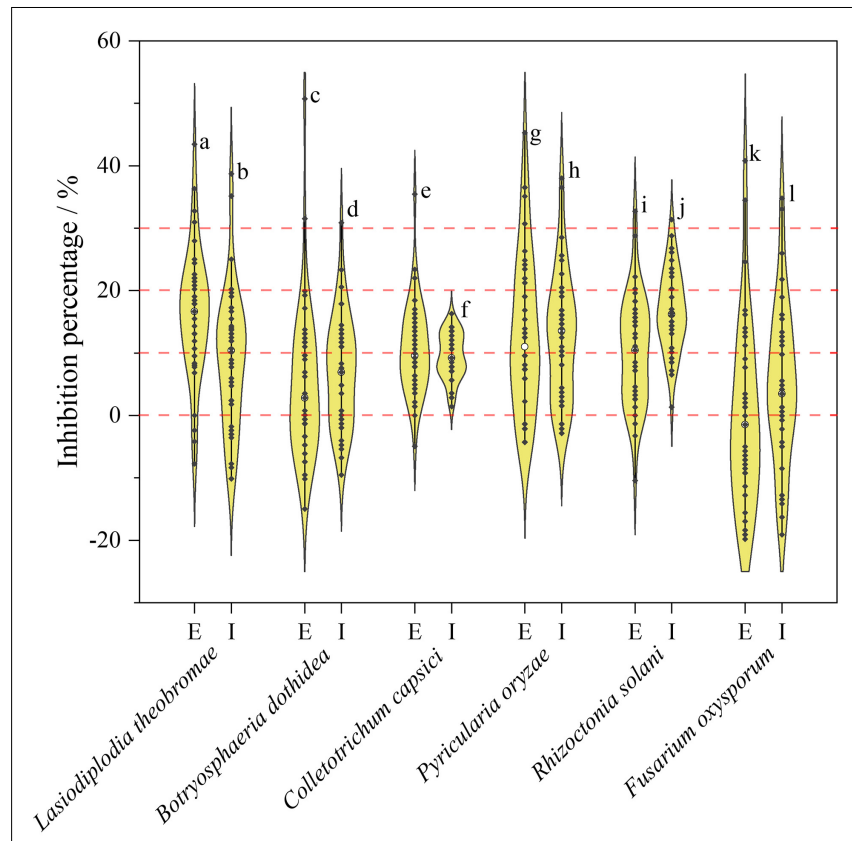

FIGURE 6 | Violin plot of antifungal activity of endophytic Sordariomycetes. The width of the violin plot represents the number of endophytic fungi at the corresponding inhibition rate. a: HGUP194009 (43.45 $\pm 1.03 \%)$; b: HGUP190070 (38.69 $\pm 2.06 \%)$; c: HGUP194009 (50.72 $\pm 2.05 \%)$; d:

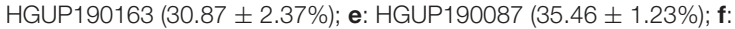

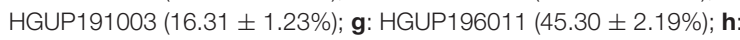
HGUP191001 (38.00 $\pm 1.26 \%) ; \mathbf{i}:$ HGUP194009 (32.68 $\pm 2.26 \%) ; \mathbf{j}:$

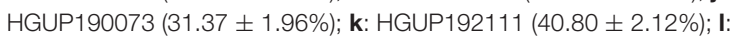
HGUP190099 (34.81 \pm 0.61\%). E, Extracellular metabolites; I, Intracellular metabolites.

Pseudomonas aeruginosa were effectively inhibited by nearly half of the selected isolates. Altogether, the results indicated that many species of endophytic Sordariomycetes exhibited broad-spectrum antimicrobial activity, such as Hypomontagnella monticulosa HGUP194009, Nigrospora sphaerica HGUP191020, and Pestalotiopsis trachicarpicola HGUP191077.

\section{Re-screening of Antifungal Activity}

Inhibition rates of secondary metabolites were displayed as a violin plot (Figure 6). Most endophytic fungi, either extracellular or intracellular metabolites, exhibited lower inhibition rates $(<30 \%)$. As observed from the trends of Figure 6, extracellular metabolites may have an advantage over intracellular metabolites in the development of antimicrobial agents. Among the extracellular products, $H$. monticulosa HGUP194009 exhibited significant inhibitory activity against Lasiodiplodia theobromae and Botryosphaeria dothidea, with $43.45 \pm 1.03 \%$ and $50.72 \pm 2.05 \%$ inhibition, respectively. In addition, Coniella sp. 2 HGUP196011 (45.30 $\pm 2.19 \%)$ and Diaporthe eres HGUP192111 (40.80 $\pm 2.12 \%)$ also displayed obvious inhibitory effects against Pyricularia oryzae and Fusarium oxysporum, in that order. Of note is that some secondary metabolites were observed in this study that may promote the growth of phytopathogenic fungi.

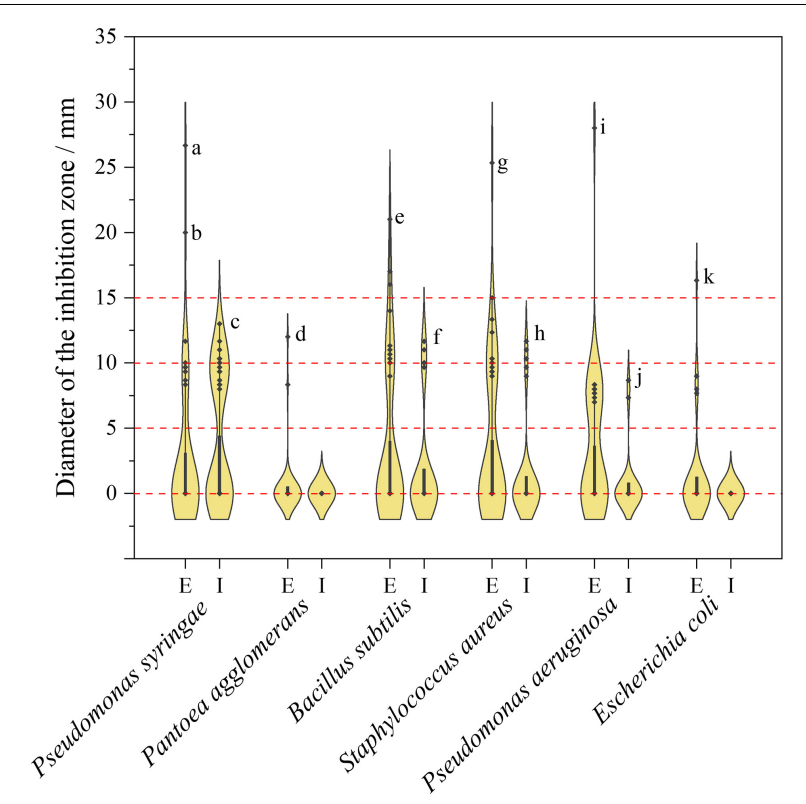

FIGURE 7 | Violin plot of antibacterial activity of endophytic Sordariomycetes. The width of the violin plot represents the number of endophytic fungi at the corresponding inhibition diameter. a: HGUP191078 (26.67 $\pm 1.53 \mathrm{~mm}) ; \mathbf{b}$ : HGUP191020 (20.00 \pm 2.00 mm); c: HGUP190043 (13.00 \pm 1.00 mm); d: HGUP191020 (12.00 $\pm 1.00 \mathrm{~mm})$; e: HGUP191020 (21.00 $\pm 1.00 \mathrm{~mm}) ; \mathbf{f}:$ HGUP190099 (11.67 \pm 0.58 mm); g: HGUP191020 (25.33 \pm 1.53 mm); h: HGUP191003 (11.67 $\pm 0.58 \mathrm{~mm})$; i: HGUP191020 (28.00 $\pm 1.00 \mathrm{~mm}) ; \mathbf{j}:$ HGUP191105 (8.67 \pm 1.53 mm); k: HGUP191020 (16.33 \pm 1.53 mm). E, Extracellular metabolites; I, Intracellular metabolites.

\section{Re-screening of Antibacterial Activity}

Violin plot of inhibition diameter of endophytic Sordariomycetes represented in Figure 7. The diameter of the inhibition zone is less than $6 \mathrm{~mm}$, which means no antibacterial activity because the diameter of the sterile filter paper disks is $6 \mathrm{~mm}$. As can be derived from Figure 7, the antibacterial activity of the extracellular metabolites was superior to that of the intracellular metabolites, which was similar to the results of antifungal activity. The diameters distributed predominantly between 8 and $12 \mathrm{~mm}$, except for those without antibacterial activity, which suggested that most metabolites of endophytic fungi had moderate or below antibacterial activity. Among the extracellular metabolites, Nigrospora sphaerica HGUP191020 showed the strongest inhibitory activity against Pantoea agglomerans, Bacillus subtilis, Staphylococcus aureus, Pseudomonas aeruginosa, and Escherichia coli compared with other endophytic strains. The isolate had a significant inhibitory effect against Pseudomonas syringae as well, with an inhibition diameter of $20.00 \pm 2.00 \mathrm{~mm}$. Additionally, Diaporthe caryae HGUP191078 also displayed strong inhibitory $(26.67 \pm 1.53 \mathrm{~mm})$ against Pseudomonas syringae.

\section{Determination of the Minimum Inhibitory Concentration}

To evaluate the antimicrobial potential of the extracellular metabolites, MICs of the isolates that exhibited a strong and 
TABLE 2 | The minimum inhibitory concentration (MIC) of extracellular metabolites against 12 tested strains.

\begin{tabular}{|c|c|c|c|c|c|c|c|}
\hline \multirow[t]{2}{*}{ Species } & \multirow[t]{2}{*}{ Strain no. } & \multicolumn{6}{|c|}{ MIC concentration $(\mathrm{mg} / \mathrm{ml})$} \\
\hline & & $\begin{array}{c}\text { Lasiodiplodia } \\
\text { theobromae }\end{array}$ & $\begin{array}{c}\text { Botryosphaeria } \\
\text { dothidea }\end{array}$ & $\begin{array}{c}\text { Colletotrichum } \\
\text { capsici }\end{array}$ & $\begin{array}{c}\text { Pyricularia } \\
\text { oryzae }\end{array}$ & $\begin{array}{l}\text { Rhizoctonia } \\
\text { solani }\end{array}$ & $\begin{array}{l}\text { Fusarium } \\
\text { oxysporum }\end{array}$ \\
\hline $\begin{array}{l}\text { Hypomontagnella } \\
\text { monticulosa }\end{array}$ & HGUP194009 & 2.50 & 1.25 & - & - & 5.00 & 10.00 \\
\hline $\begin{array}{l}\text { Nigrospora } \\
\text { sphaerica }\end{array}$ & HGUP191020 & 10.00 & - & - & 10 & - & - \\
\hline Species & Strain no. & $\begin{array}{c}\text { Pseudomonas } \\
\text { syringae }\end{array}$ & $\begin{array}{c}\text { Pantoea } \\
\text { agglomerans }\end{array}$ & $\begin{array}{c}\text { Staphylococcus } \\
\text { aureus }\end{array}$ & $\begin{array}{l}\text { Bacillus } \\
\text { subtilis }\end{array}$ & $\begin{array}{c}\text { Escherichia } \\
\text { coli }\end{array}$ & $\begin{array}{c}\text { Pseudomonas } \\
\text { aeruginosa }\end{array}$ \\
\hline $\begin{array}{l}\text { Hypomontagnella } \\
\text { monticulosa }\end{array}$ & HGUP194009 & 0.31 & 10.00 & 5.00 & 2.50 & - & 5.00 \\
\hline $\begin{array}{l}\text { Nigrospora } \\
\text { sphaerica }\end{array}$ & HGUP191020 & 1.25 & 1.25 & 2.50 & 5.00 & 1.25 & 5.00 \\
\hline
\end{tabular}

broad-spectrum inhibition in the re-screening assays were determined, as depicted in Table 2.

\section{DISCUSSION}

Although tremendous breakthroughs have been made in fungal species identification through molecular techniques, identification remains a considerable challenge for endophyterelated investigations. Morphologically, many culturable endophytic fungi fail to sporulate and are generally referred to as mycelia sterilia (Cui et al., 2021). Phylogenetically, during studies of endophytic fungi as sources of bioactive metabolites, molecular identification is typically performed using the ITS sequences or GenBank BLAST search (Raja et al., 2017; Zhang X. G. et al., 2020). However, the two approaches have distinct limitations, because they may not be able to distinguish some members with close phylogenetic relationships of certain genera (Oloo et al., 2019), and more than 1/4 GenBank fungal ITS sequences were submitted without sufficient taxonomic confirmation (Raja et al., 2017). Therefore, in this study, molecular identification was carried out using protein-coding and ribosomal genes, mainly including LSU, ITS, and TUB. Nevertheless, molecular phylogeny combined with morphology for species identification is still necessary, such as Diaporthe sp. 1 HGUP191027, Coniella sp. 1 HGUP190059, and Thelonectria sp. HGUP190169, possibly representing new taxa.

Sordariomycetes is one of the main dominant classes of fungal endophyte communities (Wang et al., 2019; Ettinger and Eisen, 2020). In this study, 242 isolates of endophytic Sordariomycetes were collected and identified from $R$. roxburghii in total, including 33 genera. The dominant genera were Diaporthe (31.4\%), Fusarium (14.4\%), Chaetomium (7.9\%), Dactylonectria (7.0\%), Graphium (4.5\%), Colletotrichum (4.1\%), and Clonostachys (4.1\%). Similar results were observed by Fang et al. (2019) in a study of the diversity of endophytic fungi from Ageratina adenophora, where the dominant genera of cultivable endophytic fungi, belonging to the class Sordariomycetes, were Diaporthe, Fusarium, and Colletotrichum. These fungal genera are common endophytic fungi from different regions and plants around the world (Paul et al., 2014; Zhu H. et al., 2019; Du et al., 2020).

Alpha diversity applied to analyze species diversity was described by the Shannon-Wiener, Simpson, Margalef, and Pielou evenness index in this work. The results revealed that the diversity of endophytic Sordariomycetes from different tissues decreased in the order of root, fruit, stem, flower, leaf, and seed. Among the endophytic fungi of Panax ginseng Meyer, the diversity index and richness of the root were higher than stem and leaf tissues (Park et al., 2017). Nevertheless, the highest diversity indexes and species richness were obtained in the stem of Zanthoxylum bungeanum (Li et al., 2016). Moreover, diversity and species richness was analyzed statistically and found to be higher in leaf than in stem segments of three medicinal plants Terminalia pallida, Rhynchosia beddomei, and Pterocarpus santalinus (Venkateswarulu et al., 2018). According to these reports, the differences of endophytic communities in plant tissues are shaped by the factors such as plant species, soil type, geographic, and environmental conditions (Xie et al., 2020). In this study, endophytic fungi, Clonostachys and Dactylonectria, also exhibited obvious tissue specificity, which may be caused by differences in the plant tissue microenvironment or the different physiology and chemistry of the colonized tissues (Li et al., 2016). Additionally, functional annotation of fungi at the genus level indicated that fungi of the same genus have multitrophic lifestyles combining endophytic, pathogenic, and saprophytic behavior. Presumably, this is because many fungi may adapt their lifestyles to various changes in host and environmental conditions by evolving into endophyte-pathogen-parasites (Zhou et al., 2018).

Antimicrobial activity, one of the important biological activities of endophytic fungi, could largely be seen as the application potential in the field of plant disease control and pharmaceutical development (dos Santos et al., 2015; Li et al., 2016). Screening for antimicrobial activity is necessary because their natural compounds possess excellent activity against plant, animal, and human pathogens (dos Santos et al., 2015; Deshmukh et al., 2018). In the present work, 242 isolates of endophytic Sordariomycetes were subjected to primary 
screening for antimicrobial activity. Then, 40 strains with antimicrobial potential were further examined, and intracellular and extracellular metabolites were prepared, respectively. In rescreening, the results suggested that extracellular metabolites may be more potential than intracellular metabolites in the development of antimicrobial agents, which is probably since most of the intracellular metabolites are not adequately secreted and released (Zhu J. et al., 2019). The results of antimicrobial assays demonstrated that there were 11 isolates with good activities, for example, Clonostachys rhizophaga HGUP190070, Coniella sp. 2 HGUP196011, Chaetomium globosum HGUP190087, Chloridium aseptatum HGUP190073, Diaporthe chimonanthi HGUP191001, D. eres HGUP192111, D. caryae HGUP191078, Fusarium sp. HGUP190163, Hypomontagnella monticulosa HGUP194009, Pseudothielavia arxii HGUP190099, and Nigrospora sphaerica HGUP191020. Among these, Hypomontagnella monticulosa with antibacterial activity has been described by Lutfia et al. (2021). Clonostachys rhizophaga has been reported to possess antifungal activity (da Silva et al., 2021). Chaetomium globosum (Kaur and Arora, 2020), Nigrospora sphaerica (Wu et al., 2018), and some Fusarium spp. (Liang et al., 2016) have previously been reported in several studies to have antimicrobial activity in vitro. To date, however, there are only a few reports on the antimicrobial activities of the other six species. From the perspective of the broad spectrum and strength, $H$. monticulosa HGUP194009 and N. sphaerica HGUP191020 were considered as isolates with great antimicrobial potential. Thus, the present results were of great promise for the development of antimicrobial agents.

Finally, we also noted that $N$. sphaerica was a fungus that caused disease on numerous plants, e.g., blueberry, tea, and palm (Wright et al., 2008; Abass et al., 2013; Dutta et al., 2015). However, in the present study and some previous studies ( $\mathrm{Wu}$ et al., 2018), N. sphaerica exhibited strong antimicrobial activities. Furthermore, N. sphaerica also exhibited anti-cancer, antiinflammatory, and $\alpha$-glucosidase inhibitory activities (Ukwatta et al., 2019). Therefore, some fungi that can cause disease may have beneficial biological activities as endophytic fungi.

\section{CONCLUSION}

In this work, with six different media, 242 strains of endophytic Sordariomycetes were isolated from R. roxburghii and

\section{REFERENCES}

Abass, M. H., Hameed, M. A., and Ahmed, A. N. (2013). First report of Nigrospora sphaerica (Sacc.) Mason as a potential pathogen on date palm (Phoenix dactylifera L.). Can. J. Plant Pathol. 35, 75-80. doi: 10.1080/07060661.2012. 732612

Agrawal, S., Samanta, S., and Deshmukh, S. K. (2021). The anti-diabetic potential of endophytic fungi: future prospects as therapeutic agents. Biotechnol. Appl. Biochem. doi: 10.1002/bab.2192

Camargo, J. A. (1992). Can dominance influence stability in competitive interactions? Oikos 64, 605-609. doi: 10.2307/3545183

Cui, L., Noushahi, H. A., Zhang, Y., Liu, J., Cosoveanu, A., Liu, Y., et al. (2021). Endophytic fungal community of Huperzia identified by multigene phylogenetic analysis. Colletotrichum, Clonostachys, Chaetomium, Diaporthe, Dactylonectria, Fusarium, and Graphium were found to be the dominant genera. The highest diversity indexes and species richness were obtained in the root tissues. Functional annotation of fungi at the genus level indicated that the same genus has multitrophic lifestyles, ranging from endophytic, saprotrophic to pathogenic. In vitro antimicrobial experiments showed that the extracellular metabolites of 11 isolates have good antimicrobial activities, especially $H$. monticulosa HGUP194009 and N. sphaerica HGUP191020. All of our results suggested that endophytic Sordariomycetes from $R$. roxburghii are potential sources for exploring antimicrobial agents.

\section{DATA AVAILABILITY STATEMENT}

The data presented in this study are deposited in the GenBank repository, accession numbers ITS: MZ724686-MZ724926; LSU: MZ724927-MZ725010; and TUB: MZ723979-MZ724131.

\section{AUTHOR CONTRIBUTIONS}

All authors listed have made a substantial, direct, and intellectual contribution to the work, and approved it for publication.

\section{FUNDING}

This work was supported by the following projects: National Key R\&D Program Projects of China (Grant No. 2017YFC1601800), National Natural Science Foundation of China (No. 32060009), and Guizhou Provincial Science and Technology Projects (No. [2020]1Y043).

\section{ACKNOWLEDGMENTS}

The authors thank Yan-Feng Han and Li Luo for their crucial help in sampling. The authors also thank Zhong Li, Xin Xie, Zhi-Bo Zhao, Hai-Xia Ding, Xian-Feng Hu, and Ying Shen for providing the tested strains.

serrata: diversity and relevance to the production of huperzine A by the plant host. Molecules 26:892. doi: 10.3390/molecules2604 0892

da Silva, H. A. O., Teixeira, W. D., Borges, ÁV., Junior, A. L. S., Alves, K. S., Junior, O. M. R., et al. (2021). Biocontrol of potato early blight and suppression of Alternaria grandis sporulation by Clonostachys spp. Plant Pathol. 70, 16771685. doi: 10.1111/ppa.13402

Deshmukh, S. K., Gupta, M. K., Prakash, V., and Saxena, S. (2018). Endophytic fungi: a source of potential antifungal compounds. J. Fungi 4, 77. doi: 10.3390/ jof 4030077

Deshmukh, S. K., Verekar, S. A., and Bhave, S. V. (2015). Endophytic fungi: a reservoir of antibacterials. Front. Microbiol. 5:715. doi: 10.3389/fmicb.2014. 00715 
dos Santos, I. P., da Silva, L. C., da Silva, M. V., de Araújo, J. M., Cavalcanti, M., and Lima, V. L. (2015). Antibacterial activity of endophytic fungi from leaves of Indigofera suffruticosa Miller (Fabaceae). Front. Microbiol. 6:350. doi: 10.3389/fmicb.2015.00350

Du, W., Yao, Z., Li, J., Sun, C., Xia, J., Wang, B., et al. (2020). Diversity and antimicrobial activity of endophytic fungi isolated from Securinega suffruticosa in the Yellow River Delta. PLoS One 15:e0229589. doi: 10.1371/journal.pone. 0229589

Dutta, J., Gupta, S., Thakur, D., and Handique, P. J. (2015). First report of Nigrospora leaf blight on tea caused by Nigrospora sphaerica in India. Plant Dis. 99:417. doi: 10.1094/PDIS-05-14-0545-PDN

Ettinger, C. L., and Eisen, J. A. (2020). Fungi, bacteria and oomycota opportunistically isolated from the seagrass, Zostera marina. PLoS One 15:e0236135. doi: 10.1371/journal.pone.0236135

Fang, K., Miao, Y. F., Chen, L., Zhou, J., Yang, Z. P., Dong, X. F., et al. (2019). Tissue-specific and geographical variation in endophytic fungi of Ageratina adenophora and fungal associations with the environment. Front. Microbiol. 10:2919. doi: 10.3389/fmicb.2019.02919

Fernando, K., Reddy, P., Hettiarachchige, I. K., Spangenberg, G. C., Rochfort, S. J., and Guthridge, K. M. (2020). Novel antifungal activity of Lolium-associated Epichloë endophytes. Microorganisms 8:955. doi: 10.3390/microorganisms8060955

Fonseca-García, C., Coleman-Derr, D., Garrido, E., Visel, A., Tringe, S. G., and Partida-Martínez, L. P. (2016). The cacti microbiome: Interplay between habitat-filtering and host-specificity. Front. Microbiol 7:150. doi: 10.3389/fmicb. 2016.00150

Gashgari, R., Gherbawy, Y., Ameen, F., and Alsharari, S. (2016). Molecular characterization and analysis of antimicrobial activity of endophytic fungi from medicinal plants in Saudi Arabia. Jundishapur J. Microb. 9:e26157. doi: 10.5812/ jjm.26157

Hajieghrari, B., Torabi-Giglou, M., Mohammadi, M. R., and Davari, M. (2008). Biological potantial of some Iranian Trichoderma isolates in the control of soil borne plant pathogenic fungi. Afr. J. Biotechnol. 7, 967-972.

Hall, T. A. (1999). BioEdit: a user-friendly biological sequence alignment editor and analysis program for Windows 95/98/NT. Nucleic Acids Symp. Ser. 41, 95-98.

Hu, C., Zhou, S. W., Chen, F., Zheng, X. H., Shen, H. F., Lin, B. R., et al. (2017). Neoantimycins A and B, two unusual benzamido nine-membered dilactones from marine-derived Streptomyces antibioticus H12-15. Molecules 22:557. doi: 10.3390/molecules22040557

Jia, M., Chen, L., Xin, H. L., Zheng, C. J., Rahman, K., Han, T., et al. (2016). A friendly relationship between endophytic fungi and medicinal plants: a systematic review. Front. Microbiol. 7:906. doi: 10.3389/fmicb.2016.00906

Kalyaanamoorthy, S., Minh, B. Q., Wong, T. K. F., von Haeseler, A., and Jermiin, L. S. (2017). ModelFinder: fast model selection for accurate phylogenetic estimates. Nat. Methods 14, 587-589. doi: 10.1038/nmeth.4285

Katoh, K., Rozewicki, J., and Yamada, K. D. (2019). MAFFT online service: multiple sequence alignment, interactive sequence choice and visualization. Brief. Bioinform. 20, 1160-1166. doi: 10.1093/bib/bbx108

Kaur, N., and Arora, D. S. (2020). Prospecting the antimicrobial and antibiofilm potential of Chaetomium globosum an endophytic fungus from Moringa oleifera. AMB Express 10:206. doi: 10.1186/s13568-020-01143-y

Kusari, P., Kusari, S., Spiteller, M., and Kayser, O. (2013). Endophytic fungi harbored in Cannabis sativa L.: diversity and potential as biocontrol agents against host plant-specific phytopathogens. Fungal Divers. 60, 137-151. doi: 10.1007/s13225-012-0216-3

Leylaie, S., and Zafari, D. (2018). Antiproliferative and antimicrobial activities of secondary metabolites and phylogenetic study of endophytic Trichoderma species from Vinca plants. Front. Microbiol. 9:1484. doi: 10.3389/fmicb.2018. 01484

Li, P., Wu, Z., Liu, T., and Wang, Y. (2016). Biodiversity, phylogeny, and antifungal functions of endophytic fungi associated with Zanthoxylum bungeanum. Int. J. Mol. Sci. 17:1541. doi: 10.3390/ijms17091541

Liang, X. A., Ma, Y. M., Zhang, H. C., and Liu, R. (2016). A new helvolic acid derivative from an endophytic Fusarium sp. of Ficus carica. Nat. Prod. Res. 30, 2407-2412. doi: 10.1080/14786419.2016.1190722

Liu, F., Weir, B. S., Damm, U., Crous, P. W., Wang, Y., Liu, B., et al. (2015). Unravelling Colletotrichum species associated with Camellia: employing ApMat and GS loci to resolve species in the C. gloeosporioides complex. Persoonia 35, 63-86. doi: 10.3767/003158515X687597

Lutfia, A., Munir, E., Yurnaliza, Y., and Basyuni, M. (2021). Chemical analysis and anticancer activity of sesterterpenoid from an endophytic fungus Hypomontagnella monticulosa Zg15SU and its host Zingiber griffithii Baker. Heliyon 7:e06292. doi: 10.1016/j.heliyon.2021.e06292

Macías-Rubalcava, M. L., Sánchez-Fernández, R. E., Roque-Flores, G., Lappe-Oliveras, P., and Medina-Romero, Y. M. (2018). Volatile organic compounds from Hypoxylon anthochroum endophytic strains as postharvest mycofumigation alternative for cherry tomatoes. Food Microbiol. 76, 363-373. doi: 10.1016/j.fm.2018.06.014

Maharachchikumbura, S. S., Hyde, K. D., Jones, E. G., McKenzie, E. H. C., Bhat, J. D., Dayarathne, M. C., et al. (2016). Families of sordariomycetes. Fungal Divers. 79, 1-317. doi: 10.1007/s13225-016-0369-6

Manganyi, M. C., and Ateba, C. N. (2020). Untapped potentials of endophytic fungi: a review of novel bioactive compounds with biological applications. Microorganisms 8:1934. doi: 10.3390/microorganisms8121934

Nguyen, L. T., Schmidt, H. A., von Haeseler, A., and Minh, B. Q. (2014). IQ-TREE: a fast and effective stochastic algorithm for estimating maximum-likelihood phylogenies. Mol. Biol. Evol. 32, 268-274. doi: 10.1093/molbev/msu300

Nguyen, N. H., Song, Z., Bates, S. T., Branco, S., Tedersoo, L., Menke, J., et al. (2016). FUNGuild: an open annotation tool for parsing fungal community datasets by ecological guild. Fungal Ecol. 20, 241-248. doi: 10.1016/j.funeco. 2015.06.006

Oloo, R. D., Okoth, S., Wachira, P., Mutiga, S., Ochieng, P., and Kago, L. (2019). Genetic profiling of Aspergillus isolates with varying aflatoxin production potential from different maize-growing regions of Kenya. Toxins 11:467. doi: 10.3390/toxins 11080467

Pal, P. P., Shaik, A. B., and Begum, A. S. (2020). Prospective leads from endophytic fungi for anti-inflammatory drug discovery. Planta Med. 86, 941-959. doi: 10.1055/a-1140-8388

Park, Y. H., Chung, J. Y., Ahn, D. J., Kwon, T. R., Lee, S. K., Bae, I., et al. (2015). Screening and characterization of endophytic fungi of Panax ginseng Meyer for biocontrol activity against ginseng pathogens. Biol. Control 91, 71-81. doi: 10.1016/j.biocontrol.2015.07.012

Park, Y. H., Kim, Y., Mishra, R. C., and Bae, H. (2017). Fungal endophytes inhabiting mountain-cultivated ginseng (Panax ginseng Meyer): diversity and biocontrol activity against ginseng pathogens. Sci. Rep. 7:16221. doi: 10.1038/ s41598-017-16181-z

Paul, N. C., Lee, H. B., Lee, J. H., Shin, K. S., Ryu, T. H., Kwon, H. R., et al. (2014). Endophytic fungi from Lycium chinense Mill and characterization of two new Korean records of Colletotrichum. Int. J. Mol. Sci. 15, 15272-15286. doi: 10.3390/ijms150915272

Peng, C., Zhang, A., Wang, Q., Song, Y., Zhang, M., Ding, X., et al. (2020). Ultrahigh-activity immune inducer from endophytic fungi induces tobacco resistance to virus by SA pathway and RNA silencing. BMC Plant Biol. 20:169. doi: 10.1186/s12870-020-02386-4

Rahaman, M. S., Siraj, M. A., Sultana, S., Seidel, V., and Islam, M. A. (2020). Molecular phylogenetics and biological potential of fungal endophytes from plants of the Sundarbans mangrove. Front. Microbiol. 11:570855. doi: 10.3389/ fmicb.2020.570855

Raja, H. A., Miller, A. N., Pearce, C. J., and Oberlies, N. H. (2017). Fungal identification using molecular tools: a primer for the natural products research community. J. Nat. Prod. 80, 756-770. doi: 10.1021/acs.jnatprod.6b01085

Rjeibi, I., Zaabi, R., and Jouida, W. (2020). Characterization of polysaccharides extracted from pulps and seeds of Crataegus azarolus L. var. aronia: preliminary structure, antioxidant, antibacterial, $\alpha$-amylase, and acetylcholinesterase inhibition properties. Oxid. Med. Cell Longev. 2020:1903056. doi: 10.1155/2020/ 1903056

Rojas, E. C., Jensen, B., Jørgensen, H. J., Latz, M. A., Esteban, P., Ding, Y., et al. (2020). Selection of fungal endophytes with biocontrol potential against Fusarium head blight in wheat. Biol. Control 144:104222. doi: 10.1016/j. biocontrol.2020.104222

Ronquist, F., Teslenko, M., van der Mark, P., Ayres, D. L., Darling, A., Höhna, S., et al. (2012). MrBayes 3.2: efficient Bayesian phylogenetic inference and model choice across a large model space. Syst. Biol. 61, 539-542. doi: 10.1093/sysbio/ sys029 
Sánchez-Fernández, R. E., Sánchez-Fuentes, R., Rangel-Sánchez, H., HernándezOrtega, S., López-Cortés, J. G., and Macías-Rubalcava, M. L. (2020). Antifungal and antioomycete activities and modes of action of isobenzofuranones isolated from the endophytic fungus Hypoxylon anthochroum strain Gseg1. Pestic. Biochem. Phys. 169:104670. doi: 10.1016/j.pestbp.2020.104670

Singh, S., Singh, U. B., Trivedi, M., Sahu, P. K., Paul, S., Paul, D., et al. (2020). Seed biopriming with salt-tolerant endophytic Pseudomonas geniculata-modulated biochemical responses provide ecological fitness in maize (Zea mays L.) grown in saline sodic soil. Int. J. Environ. Res. Public Health 17:253. doi: 10.3390/ ijerph17010253

Tilocca, B., Cao, A., and Migheli, Q. (2020). Scent of a killer: microbial volatilome and its role in the biological control of plant pathogens. Front. Microbiol. 11:41. doi: $10.3389 /$ fmicb. 2020.00041

Ukwatta, K. M., Lawrence, J. L., and Wijayarathna, C. D. (2019). The study of antimicrobial, anti-cancer, anti-inflammatory and $\alpha$-glucosidase inhibitory activities of nigronapthaphenyl, isolated from an extract of Nigrospora sphaerica. Mycology 10, 222-228. doi: 10.1080/21501203.2019.1620892

Venkateswarulu, N., Shameer, S., Bramhachari, P. V., Basha, S., Nagaraju, C., and Vijaya, T. (2018). Isolation and characterization of plumbagin (5- hydroxyl2- methylnaptalene-1,4-dione) producing endophytic fungi Cladosporium delicatulum from endemic medicinal plants. Biotechnol. Rep. 20:e00282. doi: 10.1016/j.btre.2018.e00282

Wang, Q., Hu, H., An, J., Bai, G., Ren, Q., and Liu, J. (2018). Complete chloroplast genome sequence of Rosa roxburghii and its phylogenetic analysis. Mitochondrial DNA B Resour. 3, 149-150. doi: 10.1080/23802359.2018.1431074

Wang, Y., Zhang, W., Ding, C., Zhang, B., Huang, Q., Huang, R., et al. (2019). Endophytic communities of transgenic poplar were determined by the environment and niche rather than by transgenic events. Front. Microbiol. 10:588. doi: 10.3389/fmicb.2019.00588

Wen, Z., Zeng, Z., Ren, F., and Asiegbu, F. O. (2019). The conifer root and stem rot pathogen (Heterobasidion parviporum): effectome analysis and roles in interspecific fungal interactions. Microorganisms 7:658. doi: 10.3390/ microorganisms7120658

Wright, E. R., Folgado, M., Rivera, M. C., Crelier, A., Vasquez, P., and Lopez, S. E. (2008). Nigrospora sphaerica causing leaf spot and twig and shoot blight on blueberry: a new host of the pathogen. Plant Dis. 92:171. doi: 10.1094/PDIS92-1-0171B

Wu, Z., Xie, Z., Wu, M., Li, X., Li, W., Ding, W., et al. (2018). New antimicrobial cyclopentenones from Nigrospora sphaerica ZMT05, a fungus derived from Oxya chinensis Thunber. J. Agric. Food Chem. 66, 5368-5372. doi: 10.1021/acs. jafc. 8 b0 01376

Xie, H., Feng, X., Wang, M., Wang, Y., Awasthi, M. K., and Xu, P. (2020). Implications of endophytic microbiota in Camellia sinensis: a review on current understanding and future insights. Bioengineered 11, 1001-1015. doi: 10.1080/ 21655979.2020.1816788

Xu, J., Vidyarthi, S. K., Bai, W., and Pan, Z. (2019). Nutritional constituents, health benefits and processing of Rosa Roxburghii: a review. J. Funct. Foods 60:103456. doi: 10.1016/j.jff.2019.103456

Yang, Q. Q., Zhang, D., Farha, A. K., Yang, X., Li, H. B., and Kong, K. W. (2020). Phytochemicals, essential oils, and bioactivities of an underutilized wild fruit
Cili (Rosa roxburghii). Ind. Crop. Prod. 143:111928. doi: 10.1016/j.indcrop.2019. 111928

Zhang, D., Gao, F., Jakovliæ, I., Zou, H., Zhang, J., Li, W. X., et al. (2020). PhyloSuite: an integrated and scalable desktop platform for streamlined molecular sequence data management and evolutionary phylogenetics studies. Mol. Ecol. Resour. 20, 348-355. doi: 10.1111/1755-0998.1 3096

Zhang, P., Yuan, X. L., Du, Y. M., Zhang, H. B., Shen, G. M., Zhang, Z. F., et al. (2019). Angularly prenylated indole alkaloids with antimicrobial and insecticidal activities from an endophytic fungus Fusarium sambucinum TE-6L. J. Agric. Food Chem. 67, 11994-12001. doi: 10.1021/acs.jafc.9b0 5827

Zhang, X. G., Guo, S. J., Wang, W. N., Wei, G. X., Ma, G. Y., and Ma, X. D. (2020). Diversity and bioactivity of endophytes from Angelica sinensis in China. Front. Microbiol. 11:1489. doi: 10.3389/fmicb.2020.01489

Zhao, Y., Zhang, C., Folly, Y. M. E., Chang, J., Wang, Y., Zhou, L., et al. (2019). Morphological and transcriptomic analysis of the inhibitory effects of Lactobacillus plantarum on Aspergillus flavus growth and aflatoxin production. Toxins 11:636. doi: 10.3390/toxins11110636

Zhou, J., Li, X., Huang, P. W., and Dai, C. C. (2018). Endophytism or saprophytism: decoding the lifestyle transition of the generalist fungus Phomopsis liquidambari. Microbiol. Res. 206, 99-112. doi: 10.1016/j.micres. 2017.10.005

Zhu, H., Pan, M., Bonthond, G., Tian, C., and Fan, X. (2019). Diaporthalean fungi associated with canker and dieback of trees from Mount Dongling in Beijing, China. MycoKeys 59, 67-94. doi: 10.3897/mycokeys.59.38055

Zhu, J., Yang, Y., Duan, S., and Sun, D. (2019). The antialgal mechanism of luteolin-7-O-glucuronide on Phaeocystis globosa by metabolomics analysis. Int. J. Environ. Res. Public Health 16:3222. doi: 10.3390/ijerph16173222

Conflict of Interest: G-CT was employed by Food Safety and Nutrition (Guizhou) Information Technology Co., Ltd.

The remaining authors declare that the research was conducted in the absence of any commercial or financial relationships that could be construed as a potential conflict of interest.

Publisher's Note: All claims expressed in this article are solely those of the authors and do not necessarily represent those of their affiliated organizations, or those of the publisher, the editors and the reviewers. Any product that may be evaluated in this article, or claim that may be made by its manufacturer, is not guaranteed or endorsed by the publisher.

Copyright (c) 2021 Zhang, Wei, Li, Luo, Jia, Zeng, Jiang and Tao. This is an openaccess article distributed under the terms of the Creative Commons Attribution License (CC BY). The use, distribution or reproduction in other forums is permitted, provided the original author(s) and the copyright owner(s) are credited and that the original publication in this journal is cited, in accordance with accepted academic practice. No use, distribution or reproduction is permitted which does not comply with these terms. 